\title{
The Closeness of Fit: Towards an Ecomap for the Inclusion of Pupils with ASD in Mainstream Schools
}

\author{
Mahmoud Mohamed Emam ${ }^{1}$ \\ ${ }^{1}$ College of Education, Sultan Qaboos University, Muscat, Oman \\ Correspondence: Mahmoud Emam, Department of Psychology, College of Education, Sultan Qaboos University, \\ P.O.Box 32 Al-Khod, P.C.123, Muscat, Oman. Tel: 968-9264-2084. E-mail: memam@squ.edu.om
}

\author{
Received: January 7, 2014 Accepted: February 18, 2014 Online Published: February 26, 2014 \\ doi:10.5539/ies.v7n3p112 URL: http://dx.doi.org/10.5539/ies.v7n3p112
}

\begin{abstract}
The number of pupils with autism spectrum disorder (ASD) who join mainstream schools in the UK has been increasing over the last decade. Given the difficulties in social and emotional understanding which these children have, their inclusion in schools is likely to be challenging. Their ASD-related manifestations, moreover, tend to allow for tensions to arise between them and the different systems of the school ecology. We examine the inclusion of these pupils from a developmental-systems perspective as articulated by the bio-ecological and the transactional models. Using data from a qualitative research project which explored the effect of autism-related difficulties in social and emotional understanding on the inclusion of 17 pupils with ASD the study describes the working dynamic of the arising tensions at the micro-system level. The study outlines an ecopmap of the nested structures at the micro-, meso-, exo-, macro- and chrono-systems which may facilitate or impede the children's inclusion.
\end{abstract}

Keywords: pupils with ASD, inclusion, bioecological model, transactional model, developmental systems theory

\section{Introduction}

\subsection{Introduce the Problem}

The number of educated children with ASD in mainstream schools has been increasing in the UK over the last decade (National Autistic Society (NAS), 2002, 2003). Despite their relatively high intellectual and linguistic capabilities these children retain most of the ASD-related impairments including impairment in social interaction, deviant or bizarre communication, persistent patterns of restricted and stereotyped behaviour and interests (Jordan, 1999), and difficulties in social and emotional understanding (Downs \& Smith, 2004). Given that emotions which occur in academic activities and known as academic emotions relate to pupils' learning and social outcomes (Goetz et al., 2008; Goetz et al., 2006), pupils with ASD are prone to struggle with regard to expression and recognition of such emotions, thereby minimizing the opportunity for effective interaction with peers and teachers (Hay et al., 2004; Rogers, 2000). Several scholars have argued that the ASD-related difficulties can have a negative impact on the participation and social outcomes of those pupils in mainstream schools (Humphrey, 2008; Jaher et al., 2007; Batten, 2005). In a seminal article, the author has shown elsewhere that the ASD-related difficulties in social and emotional understanding play a key role in inducing tensions which permeate the different aspects comprising the school ecosystem (i.e. peers, teachers, support, the school context) (see Emam \& Farrell, 2009). Since the publication of this article which analyzed the tensions experienced by teachers as a result of the inclusion of pupils with ASD, it has been cited several times by scholars investigating the provision of inclusive education for those pupils (e.g. Symes \& Humphrey, 2012; Parsons et al., 2011; Henderson, 2011). This has been an incentive to analyze the same data that was used in the article in addition to some related data that was not made use of in order to envisage a map for decreasing the tensions and enabling a better inclusive educational provision for children with ASD.

The traditional model of looking at ASD-related difficulties and the ensuing tensions has often focused on the children's deficiencies, assuming that such deficiencies restrict their opportunities for fitting into a social context such as that of the school (Emam \& Farrell, 2009; Wing, 1988, 1996). This focus led to the development of services and professional practices that struggle to meet the needs of those children (Billington, 2006). This traditional model, moreover, has been boosted by a number of psychological theories of autism which provided either "top-down" or "bottom up" explanations (Loveland, 2001). Top-down explanations such as the Theory of 
Mind (ToM) ability, which refers to the individual's ability to attribute mental states such as beliefs, feelings, and desires to oneself and others (Baron-Cohen, 2000), focus on cognitive deficits in the mind. Bottom-down explanations, such as the impairment in executive functions, focus on the structures of the brain and their effect on the behavioural functioning of individuals with ASD (Ozonoff, Pennington, \& Rogers, 1991). The implication of these explanations for education has been to teach pupils with ASD skills that presumably help improve their cognitive functioning (Jepsen \& Von Thaden, 2002), and social functioning (Koegel et al., 2001; Greenway, 2000), or to provide them with a lot of support (Batten, 2005; Giangreco et al., 1997).

Describing such explanations as being "mentalistic", "static" or "reductionistic", Loveland $(2001,1991)$ offers an ecological approach to understanding autism, "one that locates autism not within the head of the autistic person, but in the disordered relationship of person and environment over development" (p. 18). This approach elucidates several autistic behaviours in terms of failure to grasp the physical as well as psychological affordance which the environment offers to individuals with ASD. The study argues that the implication of this approach may further help us think of ecology of inclusion for those pupils in schools. The "ecology of inclusion" (Farrell et al., 2007; Odom et al., 2001) implies the ecological balances or closeness of fit between the resources and demands which can reflect the barriers/constraints and facilitators/affordances influencing the inclusion of pupils with ASD. Central to this ecology of inclusion is the interaction between the elements of the school context and the characteristics of the pupils with ASD. This relationship is emphasized by the developmental-systems theory (Ford \& Lerner, 2002; Lerner, 1998; Sameroff, 1993) which was successfully applied to schooling and schools (Pianta, 2001, 2006).

So, and contrary to the traditional model, the study examines the social environment of the mainstream school with an aim of identifying the "goodness of fit" vis-à-vis the mismatch between the needs of pupils with ASD and the requirements of the school context. We frame the arising tensions at the micro-system level and describe their working dynamics using a developmental systems perspective as articulated by the bioecological model (Bronfenbrenner, 2004; Bronfenbrenner \& Morris, 1998) and the transactional model (Sameroff and Fiese, 2000). The implication for education of this alternative approach is to highlight what is needed to transmute mainstream contexts to "autism-friendly" environments (Jordan, 2005, p. 108). The approach adopted by the study is compatible with Lindsay's call for a focus on 'mediators and moderators' which may have a positive effect on making inclusion effective (Lindsay, 2007). It also responds to the criticism that social contexts (e.g. schools) "surround [those children] with lifeless artefacts- unfeeling strategies stripped of meaning, that have little concern for the subtle and qualitative nature of meaningful human interaction, communication or experience" (Billington, 2006, p. 125).

\subsection{Theoretical Framework}

State why the problem deserves new research. For basic research, the statement about importance might involve the need to resolve any inconsistency in results of past work and/or extend the reach of a theoretical formulation. For applied research, this might involve the need to solve a social problem or treat a psychological disorder. When research is driven by the desire to resolve controversial issues, all sides in the debate should be represented in balanced measure in the introduction. Avoid animosity and ad hominem arguments in presenting the controversy. Conclude the statement of the problem in the introduction with a brief but formal statement of the purpose of the research that summarizes the material preceding it. For literature reviews as well as theoretical and methodological articles, also clearly state the reasons that the reported content is important and how the article fits into the cumulative understanding of the field.

Although the bioecological and transactional models were crafted from research on early childhood development, they are applicable to pupils with SEN (Kearney \& Kane, 2006; Reiter, 2003; MacDonald, 2003), including pupils with ASD (Odom et al., 2001), and are transferable across the lifespan (Renn, 2003). The bioecological model (Bronfenbrenner, 2004; Bronfenbrenner \& Morris, 1998; Bronfenbrenner \& Cecci, 1994) suggests that the interaction between the human organism and the social context is determined through the interaction of four main components: proximal processes, the person (e.g. pupils with ASD), the environmental context (e.g. the mainstream school), and the time span during which the proximal processes occur.

Proximal processes, which "are posited as the primary engines of development" (Bronfenbrenner \& Cecci, 1994, p. 572), refer to the continuous interaction with the environment including its symbols and objects, and are the means by which "potentials for effective psychological functioning are actualized" (p. 568). Characteristics of the developing person (e.g. the ASD-related manifestations) are viewed as being biologically based, having an impact on the operation of proximal processes. Bronfenbrenner and Morris (1998) conceptualize three types of the person characteristics in terms their influence on proximal processes. First is "disposition", which is 
responsible for operating proximal processes. The second type refers to the "bioecological resources of ability, experience, knowledge, and skill required for the effective functioning of proximal processes" (p. 995). The third and final type refers to the demand characteristics that encourage/discourage interaction, thereby influencing the operation of proximal processes.

The bioecological model conceptualizes the environment in terms of "nested systems or structures" (Bronfenbrenner \& Morris, 1998; Bronfenbrenner, 1979). It analyzes the functional/dysfunctional individual-environment interrelatedness across qualitatively distinctive levels: the microsystem, the mesosystem, the exosystem, the macrosysem and the chonosystem. The organized hierarchy of these nested system levels (microsystem, mesosystem, exosystem, macrosystem and chronosystem) provides a 'heuristic' which allows for a view of development as a continuum of progressing interactive processes (Fontaine, 2006, p. 65). From this perspective, pupils with ASD are at the centre of an interconnected set of contexts, including those that directly impinged on them, those that affect them indirectly (contexts at the microsystem and mesosystem levels), mediated by those with whom the pupils with ASD encounter (contexts at the exosystem and macrosystem levels).

From a biecological perspective, the ecosystem of a pupil with ASD in a mainstream school is an inclusive construct. We argue that the microsystem level includes the unique characteristics of pupils with ASD which exert an impact on their proximal processes with other school-related microsystems (e.g. relationship with and characteristic of teachers, peers, schools staff, the classroom, support resources, and pedagogy). The relationships between these microsystems constitute the mesosystems, where the focus is on 'the synergistic effects created by the interaction of developmentally instigative or inhibitory features and processes present in each setting" (Bronfenbrenner, 1993, p. 22). Support resources for pupils with ASD can be conceptualized as an exemplar mesosystem in the pupils' ecosystem.

The exosystem encompasses the processes and relationships occurring between two or more mesosystems not including the pupil with ASD in school, but which indirectly affect his/her position in school. The National Curriculum and the teachers' commitments to its application within a frame of equality policy, for example, can be viewed as an exemplar exosystem (Jordan, 2005; Jordan \& Powell, 1994). The macrosystem refers to the most distal level of environmental influence. Macrosystem effects are those at the cultural level, "with culture here considered at both the societal and within societal levels" (Tudge, Gray, \& Hogan, 1997, p. 89). Belief and value systems in schools, trends of institutional professional development, material resources, cultural tools which comprise the school culture are exemplar elements of the macrosystem.

We argue that the chronosystem or the element of time is reflected in the transition which pupils with ASD make from primary to secondary or higher educational stages and from special schools to mainstream schools. Therefore, chronosystem effects are related to the differences, changes, and stability which the pupil with ASD may experience during his/her transition across the lifespan as well as the nested system of their ecosystem. Bronfennbrenner and Morris (1998, p. 995) argued that microtime reflects the continuity vs. the discontinuity of proximal processes. Mesotime reflects the "periodicity" of continuous or discontinuous proximal processes "at broader time intervals", whereas macrotime refers to the change of expectations across stages of development.

The transactional model (Sameroff \& Fiese, 2000) similarly highlights the interaction between the characteristics of the individual and the given social environment in which he is placed. It, however, does so with an aim of developing ecologically based prevention and intervention strategies. Adapting the transactional model to the inclusion of pupils with ASD, the study argues that there is an interconnectedness among the ASD-related manifestations (the phenotype) which are biologically based (the genotype), and the organization of experiences (the environtype) in their ecological niche (e.g. opportunities for development offered by mainstream schools) in determining the developmental (social and emotional), and leaning outcomes.

Building on both models (depicted in Figure 1), the study argues that the interaction between the ASD-related characteristics and the nested systems of their school context is a key determinant of their developmental outcomes in school. The responsiveness of these systems and the quality of their environtype are likely to help them to maximise the chances that pupils with ASD in mainstream schools can adapt to their school's ecosystem. Based on a research project which explored the effect of autism-related difficulties in social and emotional understanding on the inclusion of 17 pupils with ASD, the study examines the working dynamics of the pupils' microsystem features, highlighting the effect of their social and emotional understanding-related characteristics on the operation of proximal processes with their school ecosystem. In so doing, the study addresses the affordances/constraints which may affect the inclusion of those pupils due to their unique characteristics. 


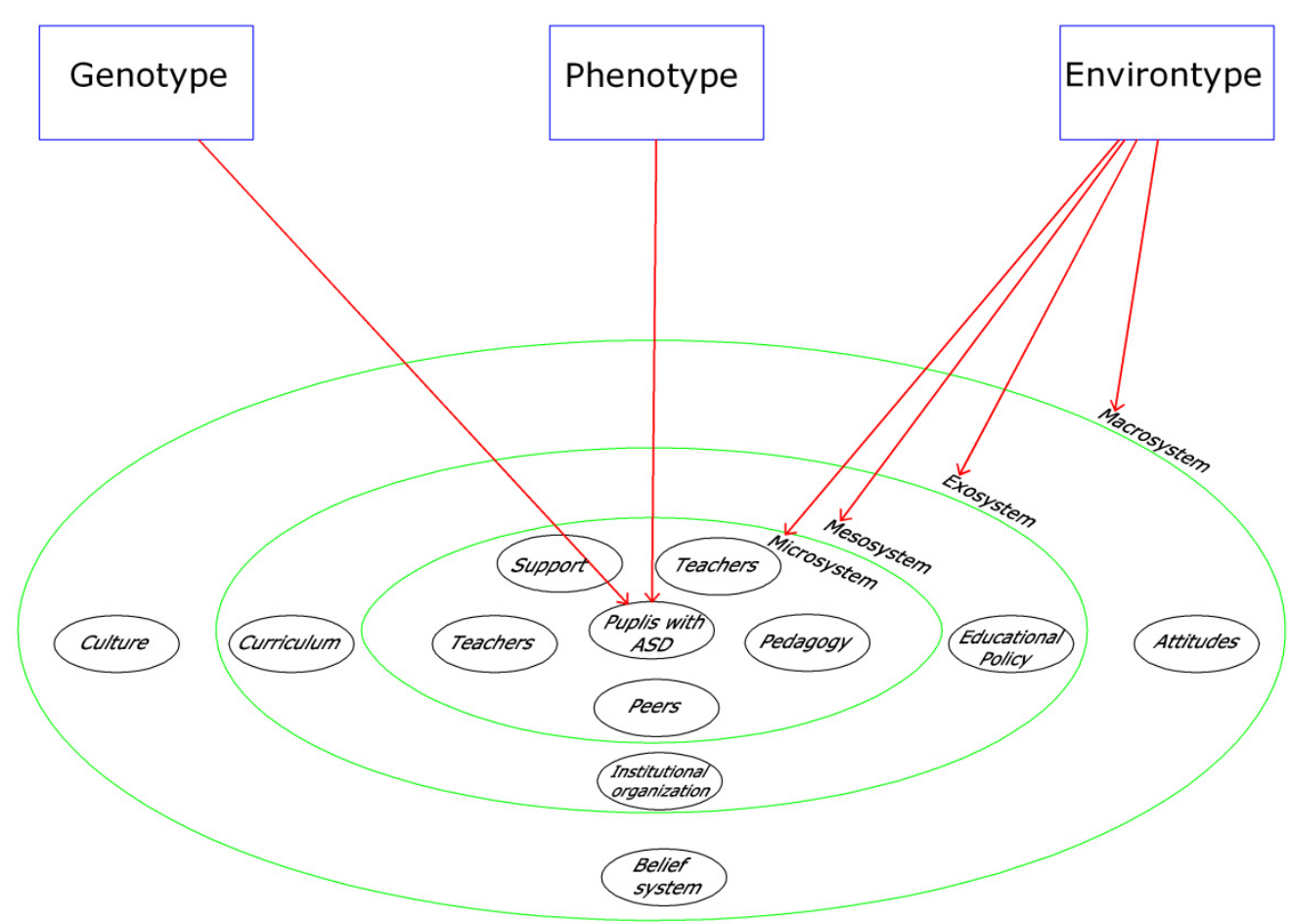

Figure 1. The ecosystem of pupils with ASD in mainstream schools: A developmental systems conceptualization

\section{Method}

The empirical study and the data which follow are drawn from a larger research project carried out during 2005-2008, which argued for a notion of "ecology" of inclusion for pupils with ASD in mainstream schools (Emam, 2008). The project comprised of in-depth 17 case studies of pupils with ASD in primary and secondary schools in the north-west of England. Table 1 provides a generic description of the participants. Following a multiple case study design (Yin, 2003; Stake, 2006; Miles \& Huberman, 1994) data was collected through conducting interviews with teachers, teaching assistants (TAs), and special educational needs coordinators (SENCOs). In addition participants were observed inside and outside the classroom, and administered two psychological measures: School conflict Measure (SCM) (developed by the authors), and Levels of Emotional Understanding Questions (LEUQ) (Howlin et al., 1999). However, the research reported in this study focuses solely on data drawn from interviews and observation.

Using Atlas Ti 5.2 qualitative analysis software, the data from interviews and observation was initially coded to generate theoretical codes to allow for drawing conclusions about individual cases as the first phase of analysis (Charmaz, 2006; Strauss \& Corbin, 1998). The second phase of analysis consisted of a thematic anatomization of the theoretical codes within and across cases (Boyatziz, 1998), and explanation building as well as pattern matching of commonalities and differences among the 17 participants (Yin, 2003). Our aim was to reach a conceptual network which reflects the effect of the ASD-related characteristics on children's microsystem in school. We also were interested in exploring the working dynamics of this microsystem on the transactions between the pupils with ASD, their teachers, their peers, and school context. 


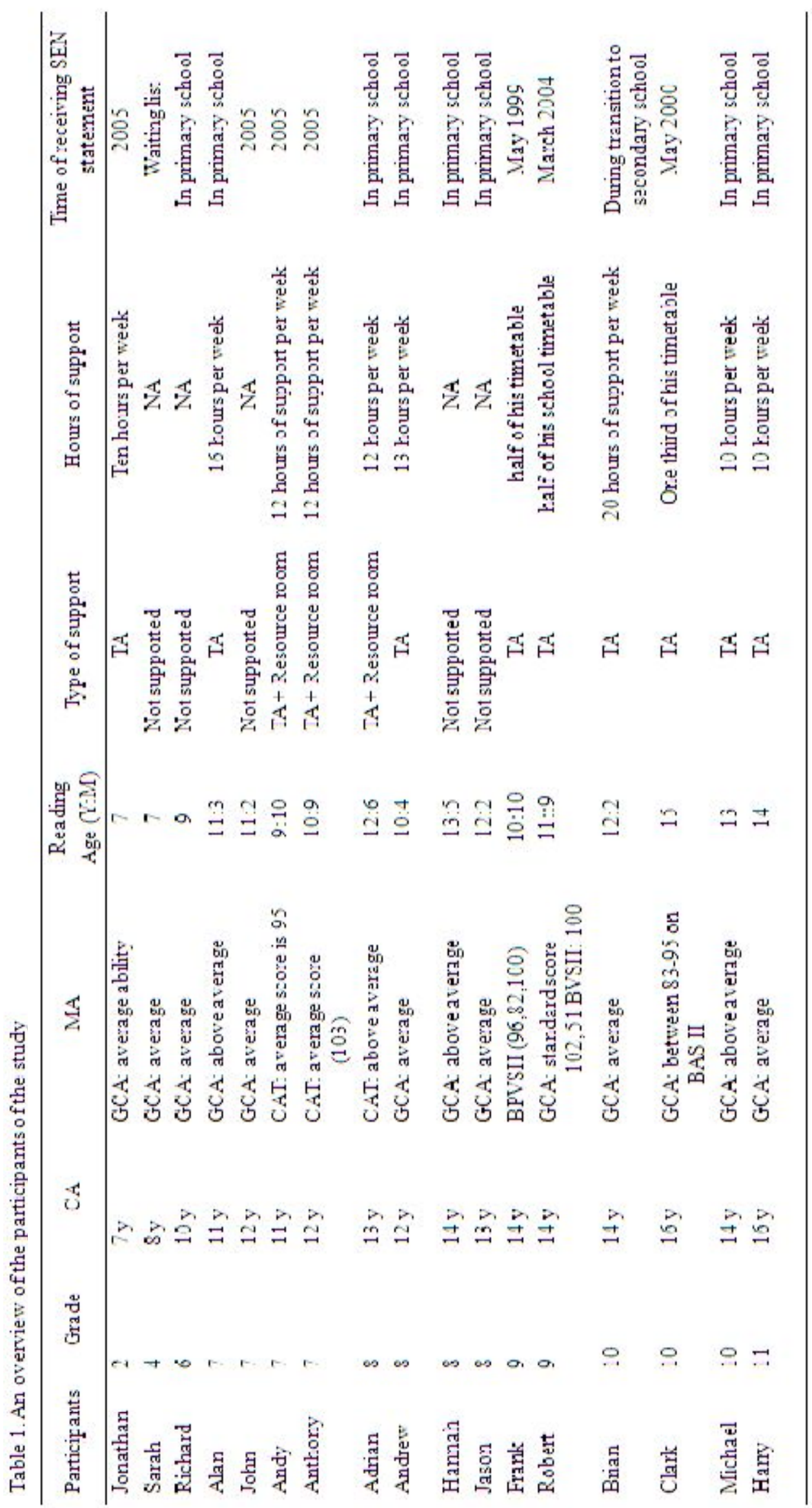




\section{Findings and Discussion}

In general the social and emotional understanding-related manifestations were highlighted as being crucially influential on the interaction between pupils with ASD and the components of their school ecosystem. Three theoretical clusters were synthesized at the microsystem level, which reflected its working dynamics, and determined the quality of the occurring proximal processes. These theoretical are presented and discussed in what follows:

- Developmental differences as a circular causal system.

- ToM as an antecedent and buffer zone system.

- Academic emotions as a boundary system.

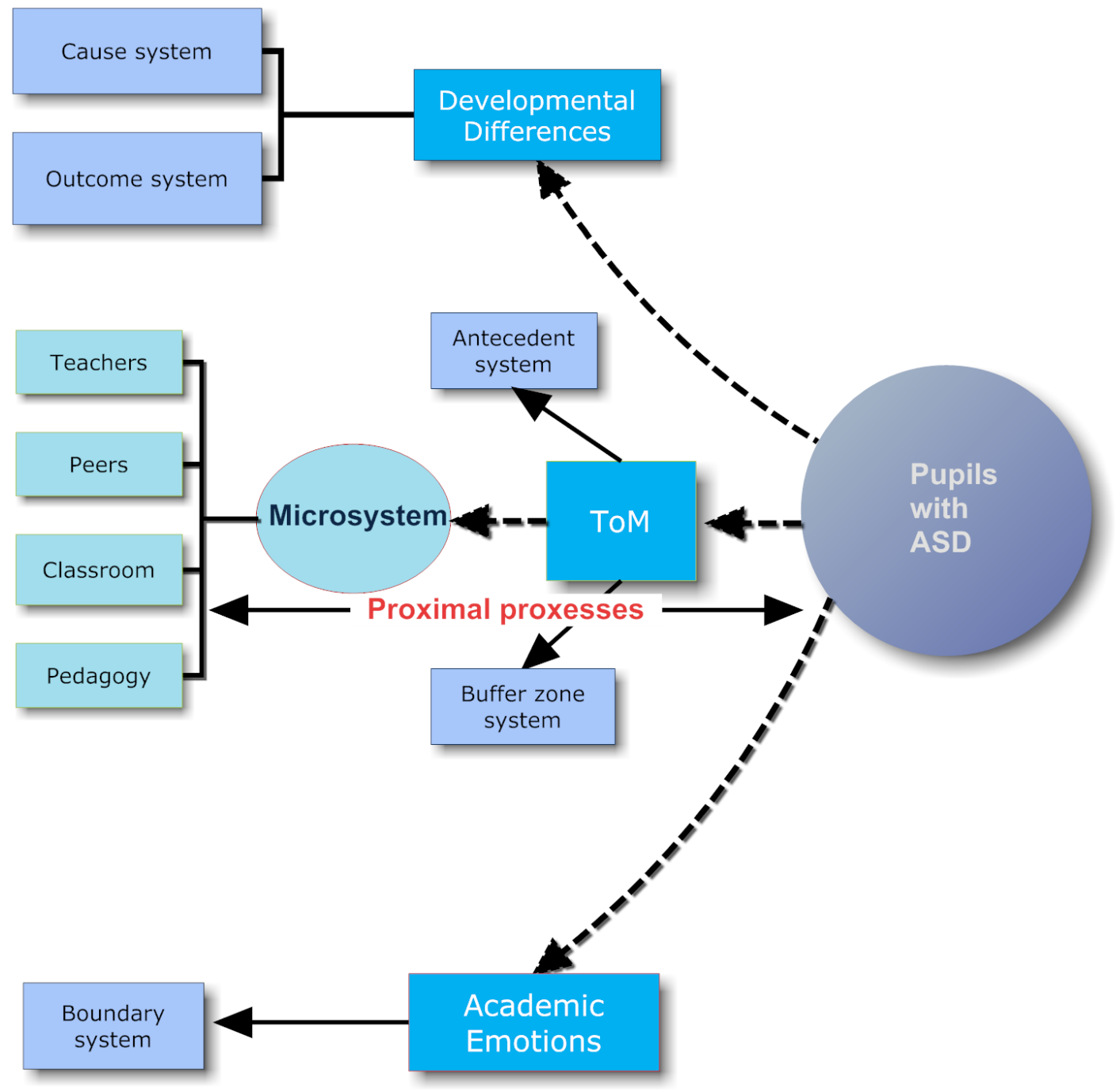

Figure 2. A conceptual network of the working dynamics of the microsystem effects on proximal processes between pupils with ASD and their school ecosystem

\subsection{Developmental Differences as a Circular Causal System}

Provide dates defining the periods of recruitment and follow-up and the pnmary sources of the potential subjects, where appropriate. If these dates differ by group, provide the values for each group.

We found that developmental difference explicitly distinguish between the participants and their peers in school. They determine the likelihood of the occurrence of tensions between the pupils with ASD and their teachers and peers. These differences were shown in the data to work as a cause as well as an outcome influencing their own 
cause. The description provided for the participants by their teachers and TAs reflected these differences. Descriptions such as "geeky", "eccentric", "mad professor", "motor bully", and "nightmare" reflect how the participants are stereotyped in mainstream schools. The participants" tendency to refrain from social interactions in the classroom as well as the broader school context is the main characteristic of their developmental differences as seen by their teachers and peers. This characteristic appears to pose enormous challenges to teachers:
"He had what I used to call TUNNEL VISION and used to just to look down at that tunnel and saw everything and everyone as being not more important than what he was doing unless it was something he did not like." (TA, Clark)

The participants' ASD-related manifestations which represent the core of their developmental differences place considerably different demands on teachers' shoulders. This is because they affect the participants' adaptation to the mainstream context, their social, emotional and learning outcomes. The data showed the participants to require major teaching differentiation and curricular modifications. The typical difficulty of the participants with routine change enormously destabilizes the participants during transitional periods:

\begin{abstract}
"One incident last year we had at the start of his GCSE. He found himself with ten new teachers...ten new classrooms... and it took him so long to settle down with the new routines...he was missing lesson a lot...these sort of things created problems for Brian and for his learning" (SENCO interview, Brian)
\end{abstract}

Furthermore, the developmental differences between the participants and their peers appear to create a number of dilemmas for teachers, which mould potential tensions. Such dilemmas take different forms. The teachers, for example, may become incapable of following the equal policy dictated by schools in dealing with the pupils due to incapability to overlook the influence of the participants' ASD-related manifestations on their behaviours. Therefore, they sometimes fail to resolve the several conflicts that occur between the participants and their peers in class. These dilemmas increase for teachers in secondary schools as compared to teachers in primary schools due to the peers' intolerance towards the participants' manifested developmental differences at that stage:

\begin{abstract}
"The teaching has to stop in order to resolve the conflict... and the inclusion policy we have is that we have to treat him equally as the other students...therefore...there have to be reprimands" (Teacher interview, Harry)
\end{abstract}

Teachers are likely to rely on verbal as well as non-verbal communication in interacting with all pupils. The presence of the participants in class, however, places restrictions on the teachers' conscious and unconscious use of body and face signals. The teachers were inclined to draw comparisons between the participants and their peers. Such comparisons, which can be argued to be unfair in the first place, shadow the teachers' daily interactions with the participants. Bronfenbrenner and Morris (1998) argued that proximal processes may emphasize either dysfunction of competence. The data showed that teachers engage in proximal processes in order to reduce dysfunction rather than enhance competence. This was typical of secondary school participants and was less apparent in the case of primary school participants.

The participants' developmental differences appear to delineate a demarcation between primary and secondary mainstream schools in terms of the effect on their ecosystem. In the light of the data, the participants' developmental differences have less impact on primary school teachers than on secondary school teachers. Teachers in primary school have better opportunities to explore and discover the participants because the school system is based on the one classroom teacher. Through this exploration the teacher reflects on how to manage the participant's behaviour in the best way based on the training or information he attains from the SENCO. Richard emerges as an exemplar case of this argument. The long time his teacher spends with him is shown to have helped her identify his strengths to build on, and his difficulties to address, which has resulted in crystallizing the best way of managing him in the classroom context. Hence she is able to judge that the best way to deal with Richard's inappropriate behaviour is not to react, shout or "tell him off" because "this pleases him", and reinforces such behaviours.

Alternatively, teachers in secondary schools were shown to occasionally interact with the participants in this "hustly bustly environment". They see them in specific classes and therefore they are unlikely to show commitment to them. They tend to have an inner dialogue of "I am not responsible" when they see the pupil for the limited time of the class they deliver. The logic of Richard's teacher is that "It is much easier for the teacher to teach in a different way" to "get along with him" than to ask Richard to behave differently, whereas the logic 
of Andy's teachers is "I do not know whether I should enforce him and enforce my opinion over Andy...I just listen to what the TA says to me."

As for the effect of the developmental differences on peers, although primary and secondary schools commonly share a poor relationship between the participants and their peers, this manifests itself differently. The developmental differences are less invisible to peers in primary schools due to the peers' developmental incapability to detect and reflect upon the participants' differences. Peers are unlikely to judge pupils with ASD based on their difference. Therefore, peers are unlikely to intentionally bully them. Notwithstanding participants' observed avoidance of them, peers tended to "mother" them. This 'mothering' approach, however, does not create a close friendship between pupils with ASD and their peers. Teachers report that the participants are incapable of developing a close friendship with peers.

In secondary schools, however, the poor communication between the pupils with ASD and their peers takes the form of negative interaction outcomes. During observation, the participants were seen to be teased and satirized by their peers. Moreover, they were reported to face bullying in secondary schools either implicitly or explicitly. The poor relationship between the pupils with ASD and their peers, which was recorded in observation, may be attributed to the participants' incapability to discern what their peers afford to them during the occurring proximal processes. The description "he is nice, generous, kind person who is misunderstood by his fellow peers really" which is given by Harry's teacher, apparently, applies to all the secondary school participants in the study; and depicts the overall picture of the effect of their developmental differences on their inclusion.

Teachers and TAs' views of the pupils with ASD' academic learning outcomes are further influenced by their manifested developmental differences. Whereas teachers doubt the participants' capability of doing "GCSE" while "all this support is going on with them", TAs posit that the participants have a lot of potential which may enable them to "carry on till the university". These contradictory views elucidate the extent to which the participants' developmental difference may mask their strengths and potentials sometimes. TAs form their views based on the long time they spend with them and the response they show to them in daily interactions, whereas teachers place the pupils' competence in comparison with the larger picture of the requirements of the National curriculum.

\subsection{ToM as an Antecedent and a Buffer Zone System}

ToM represents a second component of the microsystem. ToM is a cognitive component in the first place although its function is social. As a social cognitive element, ToM facilitates interaction through reading others' feelings, beliefs, and thoughts in a social context such as the mainstream school. The data shows ToM to have an impact on the participants' ecosystem in school. It is inextricably woven into the tensions which they face or pose to teachers and peers. We found that ToM is an essential parameter for the quality of the occurring proximal processes. However, the explanation of this construct tends to be ecological. We argue that ToM works as both an antecedent and a buffer zone system for the occurring proximal processes.

Because of struggling with identifying the intentions of teachers in terms of their actions and emotions, pupils with ASD misunderstand the affordances which are conveyed within teachers' orders, instructions and behaviours in the classroom. In this respect, ToM may be argued to work as an antecedent system for the arising tensions. The participants, for example, are unlikely to understand that teachers' instructions are communicated to the whole class. This is why they do not act or engage in an activity until the instructions are relayed on a personal basis:

\section{"If we were sitting on the carpet talking about something and then you tell all the children to go and do it, he will look confused" (Teacher interview, Jonathan)}

Similarly, ToM works as an antecedent to the teachers' dissatisfaction with the performance of the pupils with ASD on academic tasks. Although teachers prioritize the perfection of academic tasks by pupils, the pupils with ASD are incapable of understanding what perfections affords to them in terms of learning achievement outcomes:

"part of the mark scheme is to put some colours on any design or drawings they make... and quite often after they finish their drawing ...I say like "come on put some colours on this" but they can not understand that this is important for the mark scheme...so they can not put themselves in my shoes when I ask them to do that; so they are like "no we are not doing this" (Teacher interview, Andy, and Anthony) 
Alternatively, ToM was found to work as a buffer zone system which triggers teachers' forgiveness, excuses, and tolerance in school. Teachers, for example, are likely to become too confused to judge the intentionality of the inappropriateness of the pupils' behaviours. Unlike their typically developing peers whose intentions are explicitly manifested in their actions, the participants' intentions are obscured by their deficient ToM. Teachers, in such situations, tend to cautiously circumvent blaming them. ToM as a buffer zone system, nevertheless, appears in the data to work better in primary schools compared to secondary schools. Whereas teachers in primary schools tend to excuse those pupils for much of their displayed behavioural problems, teachers in secondary school show intolerance for such pattern of behaviour.

Similarly, a similar impact of ToM on the participants' relationships with their peers was found. The participants' deficient ToM provides a space for tension to arise between both sides. The data shows an association between the participants' capability of interpreting their peers' intentions, emotions and beliefs and the quantity as well as the quality of interaction between them either in classroom-based activities or at break and play times. Because of the participants' incapability to "mentalize' peers" position during interaction situations in terms of the "cheek" which characterizes such situations, tensions tend recur. When tension arises, the participants react by either complaining to the teachers or circumventing similar future situations. In both cases, the peers begin to 'distance' themselves from the participants in the same way the participants 'distance' themselves. In this regard, ToM can be argued to represent the antecedent to the participants-peers avoidance pattern in the mainstream school.

However, ToM as a buffer zone system did not function in the occurring proximal processes between the participants and their peers. This applies to both primary as well as secondary school contexts. One reason is that peers in primary schools are not developmentally able to identify the participants' incomplete or deficient ToM, while peers in secondary schools are tolerant enough to allow the participants' ToM to work as a buffer zone system:
"He wants everything to be fair... and in that respect he is isolated by others... when he tells of anything wrong they do...because he also criticizes them and therefore he does not play the game socially in that respect...he does not identify with other pupils' emotions at all...and that makes it difficult for him" (Teacher interview, Brian)

As a social cognitive component, ToM is presumed to facilitate the understanding of the social demands of school context. However, the data unfolded the participants' disregard of the social aspect of the mainstream context. Such disregard the failure on their part to discern what vibrancy of school interactions, both academic and social, affords to them. They, for example, are incapable of conceiving friendship as a mechanism for social engagement and as a social process within the school context.

\section{"He seems that school is happening to him. He comes to school and all the hustle and bustle it all happening around him and he seems like a little island in the middle of it. We interact with him. To me he never asked me for anything, he never asked my help or guidance, opinion or anything, so whenever I answer him it is on my own terms." (Teacher interview, Robert)}

Furthermore, the complexity of ToM lies in its embedment in more complex school based activities whether social or academic. This is why Richards' primary school teachers were concerned about his impending transition to secondary school. Their concern springs from the immense difference between both contexts in terms of the levels of vibrancy, bullying and violence. The ecology of inclusion in primary school provides the participant with "a family" atmosphere which mollifies the complexity level of the context. Within this family atmosphere, teachers help explain and make explicit what is embedded in interaction situations, be they academic or social.

\subsection{Academic Emotions as a Boundary System}

The structure of a mainstream school represents a system which includes a number of sub-systems all of which are differentiated by boundaries, i.e. non-physical dividers which separate the systems or sub-systems from each other. In this regard, academic emotions, which refer to emotions that occur within academic school setting and are directly linked to learning, classroom instruction, and achievement (Pekrun et al., 2002), can be viewed as a key boundary system. This boundary system has an impact on the occurring proximal processes within the school ecosystem of pupils with ASD. Examples of academic emotions include enjoyment of learning, embarrassment from lack of participation, and anxiety about learning outcomes. The participants' lack of, or at best struggle with such academic emotions were reported by teachers, recorded in observation and reflected in their responses on the SCM (Emam \& Farrell, 2009). Such struggle with academic emotions has a negative 
impact on the opportunities for interaction which the schoo context offers, and on the school boundary system represented in its symbol rules and conventions. This prevents them from engagement with other social agents, i.e. teachers and peers, thereby, restricting the potential benefits produced by the occurring school transactions.

Academic emotions are essential signals and cues which presumably stimulate pupils in the learning environment. However, the difficulties which the participants were reported to show in recognition and expression of such emotions during academic and social school activities simulate tension between them and their teachers as well as peers. The participants' limited repertoire of academic emotions which is reported by teachers to affect their social engagement in schoo. The teachers tend to view the participants' incapability of emotionally connecting to other peers in class as a preference rather than as an ASD-related manifestation:

\section{"Hannah seems to be non-emotional especially if we consider that the class she is in is a lovely class... all of them are interacting and laughing with each other...she seems just to sit and watch them...she does not interact as the other children do" (Teacher interview, Hannah)}

Teachers' dissatisfaction grows further when the effect of the participants' difficulties with expressing and recognizing emotions extend to their academic and learning outcomes, particularly in academic subjects such as English and Drama in secondary school. This is because teachers show concern regarding the participants' academic outcomes in general:

\section{"She does not seem extremely embarrassed. She will perform but with sort of no reference to having any concern about anybody. She will perform and sit down" (Teacher interview, Hannah)}

Notwithstanding the participants' limited repertoire of academic emotions they display a few of them. However such display often appears in form that is different from that displayed by other typically developing peers. Therefore, they stand out as being different in engendering the repertoire which they possess:

\section{"I see him embarrassed by little and small things...but again in a way that reflects what in another would be seen as immaturity". (Teacher interview, Adrian)}

Even though the participants were reported to identify basic emotions such as anger, happiness and sadness, they do not respond to these emotions unless they are strongly expressed by peers and teachers. The participants were observed to be puzzled during learning activities during classroom activities. They were observed not to follow the same stream of behaviours or actions which their peers follow during learning activities, unless they are prompted by the teacher of TA on personal basis. Unsurprisingly, therefore, the participants do not take part in classroom activities on a self-initiative basis. They were reported to be 'held back', from participating in classroom-based activities. This reflects the failure to read the emotional affordance which should encourage rather than discourage them to engage in these activities.

We found that the participants' obliviousness to complex emotions in interaction situations renders them excluded in most cases. The 'mask' which covers their emotional reactions during the occurring proximal processes works as a boundary system which blocks other peers from proximal interactions or engagement in academic and social activities. The data shows the participants to set up their own boundary system due to their inability to respond to the emotional and social affordances of the school context. A teacher refers in an interview to Michael's "room syndrome", to reflect the preference to determine his own boundaries. These boundaries, however, clash with the spontaneous flow of interactions which characterizes the school ecosystem:

\section{"Michael has what I call room syndrome... when someone enters the room by imposing a boundary that when he shuts the room" (Teacher interview, Michael)}

The participants' interest in expressing their emotions which usually fulfils their own desires and needs, i.e. dispositions, clashes with the boundary system created by school rules and social conventions, thus discouraging teachers and peers from interacting with them, i.e. demand characteristics. Such clash affects the participants' social outcomes in terms of their communication with others, particularly teachers. It, moreover, triggers the teachers' intolerance as well as frustration unless they show willingness to compromise. It is not surprisingly, therefore, that Michael expresses himself well in the English class because the teacher adopts such compromise:

"He understands the rules in my classroom...you know why? there are no rules...I go to the classroom.....and say I am the teacher and this is what we are going to do...I do not impose rules...I believe in the relationship with 
people and not dominating people through authority...I tell the head of department that I have rules but not the pupils.... [and this is confidential by the way]...for me let the rules develop...let the pupils make the rules" (Teacher interview, Michael)

With regard to emotions in general, the data showed that the participants' emotions work as a reversible boundary system. They dislike boundaries to be imposed on them by others when they express themselves emotionally, although they prevent others from crossing their boundaries. This is why being more of 'a loner' is a typical description given by teaches about the participants behaviour inside the classroom.

\section{Conclusion}

Cognitive and socioemotional characteristics of individuals have often been though of as measures of developmental outcomes and not as precursors or producers of later development (Bronfenbrenner and Morris, 1998). We argued in this paper that the developmental systems perspective considers the influence of these characteristics on the emergence and operation of proximal processes with a given environment. Applying theoretical frameworks can be helpful improving educational policy and practice in the area of inclusive education. We argued that the developmental systems theory as represented in the bioecological model and the transactional model can serve as heuristic platform for exploring the ecology of the inclusion of pupils with ASD in mainstream schools.

This approach suggests that schools can provide opportunities and affordances for the learning and development of those pupils by adopting a holistic consideration of the occurring proximal processes between the static and dynamic features which form school ecology. Examples of static features include academic materials, pedagogical practices, support resources, and application of the National Curriculum, whereas attitudes and skills repertoire of teachers and peers, the availability of peer culture in school, school culture and belief system regarding inclusion as a practice rather than a policy are examples of the dynamic features. Both features should afford the unique characteristics of pupils with ASD. The collective experiences springing from these features of school ecology represent the "enviorntype" code which can be the basis for establishing benchmarks of transmuting our schools to be "autism friendly" environments.

From the developmental systems perspective, intervention and prevention tend to be ecologically based. Remediation strategies have long been adopted to change pupils with ASD by providing interventions which target the cognitive, behavioural and social aspects of functioning. We argue that these strategies, albeit important, minimize the pupils' chances to benefit from inclusive educational practices. Equally important from my point of view is the focus on re-education and re-definition strategies. Redefinition strategies include altering the teachers' expectations and beliefs about the capabilities and potentials of pupils with ASD when they are included in mainstream schools. They include changing the way the teachers interpret the child's behaviour. So instead of focusing on the ASD-related manifestation and attributing pattern of maladaptaion to these difficulties, the teachers are refocused on other attributes and strengths so as to facilitate positive engagement. Re-education changes the way the teachers behave and act towards the pupil with ASD. This can be achieved through providing special training to teachers and through emphasizing collaboration between teachers and support teachers. The implication of thinking of the ecology of inclusion is likely to highlight what is needed to transmute mainstream contexts to "autism-friendly" environments (Jordan, 2005), and minimize any fears of potential negative effects of inclusion (Farrell et al., 2007).

Finally, the study assumes that the adopted approach is not without limitations, nor was the research design. Interviewing teachers, TAs, and SENCOs in addition to observation may not provide a sufficient frame of reference to explore the barriers and facilitators of the inclusion of pupils with ASD in schools. Positivist empirically based data and experimental designs, if possible and ethical, may further ground for this approach in future research.

\section{Acknowledgements}

The author would like to thank Professor Peter Farrell at the University of Manchester, who has recently retired, for his editorial remarks on this paper and for his supervision of the work reported in this article. The work reported in this article is part of a research project which the author undertook as part of his $\mathrm{PhD}$ degree at the University of Manchester, college of education.

\section{References}

Attwood, T. (2000). Strategies for improving the social integration of children with Asperger syndrome. Autism, 4, 85-100. http://dx.doi.org/10.1177/1362361300004001006 
Baron-Cohen, S. (2000). Theory of mind and autism: A fifteen year review. In S.Baron-Cohen, H. T. Flusberg, \& D. J. Cohen (Eds.), Understanding other minds: Perspectives from developmental cognitive neuroscience (2nd ed.). Oxford: Oxford university press.

Batten, A. (2005). Inclusion and the autism spectrum. Improving Schools, 8(1), 93-96.

Boyatzis, R. (1998). Transforming qualitative information: Thematic analysis and code development. Thousand Oaks: Sage Publications.

Bronfenbrenner, U. (1979). The ecology of human development: Experiments by nature and design. Cambridge, MA: Harvard University Press.

Bronfenbrenner, U. (1992). Ecological systems theory. In R. Vasta (Ed.), Six theories of child development: Revised formulations and current issues (pp. 187-249). London: Jessica Kingsley.

Bronfenbrenner, U. (2004). Making human beings human: Bioecological perspectives on human development. Thousand Oaks, CA: Sage Publications.

Bronfenbrenner, U., \& Ceci, S. (1994). Nature-nurture reconceptualized in developmental perspective: A bioecological model. Psychological Review, 101, 568-586.

Bronfenbrenner, U., \& Morris, P. (1998). The ecology of developmental processes. In W. Damon, \& R. M. Lerner (Eds.), Handbook of child psychology: Theoretical models of human development (pp. 993-1028). New York: Wiley.

Charmaz, K. (2006). Constructing grounded theory: A practical guide through qualitative analysis. London: Sage Publications.

Downs, A., \& Smith, T. (2004). Emotional understanding, cooperation, and social behaviour in high-functioning children with autism. Journal of autism and developmental disorders, 34(6), 625-635. http://dx.doi.org/10.1007/s10803-004-5284-0

Emam, M. (2008). The social and emotional understanding-related impairments of pupils with autism spectrum disorder in mainstream schools: A study of the ecology of inclusion. University of Manchester.

Emam, M., \& Farrell, P. (2009). Tensions experienced by teachers and their views of support for pupils with ASD in mainstream schools. European Journal of Special Needs Education, 24(4), 407-422. http://dx.doi.org/10.1080/08856250903223070

Farrell, P., Dyson, A., Polat, F., Hutcheson, G., \& Gallannaugh, F. (2007). SEN inclusion and pupil achievement in English schools. Journal of Research in Special Educational Needs, 7(3), 172-178.

Fontaine, R. G. (2006). Applying systems principles to models of social information processing and aggressive behaviour in youth. Aggression and Violent Behaviour, 11, 64-76.

Giangreco, M., Edelman, S., Luiselli, T., \& MacFarland, S. (1997). Helping or hovering? Effects of instructional assistant proximity on students with disabilities. Exceptional Children, 64, 7-18.

Goetz, T., Frenzel, A. C., Hall, N. C., \& Pekrun, R. (2008). Antecedents of academic emotions: Testing the internal/external frame of reference model for academic enjoyment. Contemporary Educational Psychology, 33, 9-33. http://dx.doi.org/10.1016/j.cedpsych.2006.12.002

Goetz, T., Pekrun, R., Hall, N., \& Haag, A. L. (2006). Academic emotions from a social-cognitive perspective: Antecedents and domain specificity of students' affect in the context of Latin instruction. British Journal of Educational Psychology, 76, 289-308.

Hay, D. F., Payne, A., \& Chadwick, A. (2004). Peer relations in childhood. Journal of Child Psychology and Psychiatry, 45(1), 84-108. http://dx.doi.org/10.1046/j.0021-9630.2003.00308.x

Henderson, K. (2011). Policies and Practices Used by States to Serve Children With Autism Spectrum Disorders. Journal of Disability Policy Studies, 22(2), 106-115. http://dx.doi.org/10.1177/1044207310396210

Howlin, P., Baron-Cohen, S., \& Hadwin, J. (1999). Teaching children with autism to mind-read: A practical guide for teachers and parents. Chichester: Wiley.

Jaher, E., Ikeseth, S., Eldevik, S., \& Aase, H. (2007). Frequency and latency of social interaction in an inclusive kindergarten setting: A comparison between typical children and children with autism. Autism, 11(4), 349-363. http://dx.doi.org/10.1177/1362361307078134

Jepsen, R. H., \& Von Thaden, K. (2002). The effect of cognitive education on the performance of students with 
neurological developmental disabilities. NeuroRehabilitation, 17, 201-209.

Jordan, R. (1999). Autistic Spectrum Disorders: An introductory handbook for practitioners (1st ed.). London: David Fulton.

Jordan, R. (2005). Managing autism and Asperger's syndrome in current educational provision. Paediatric Rehabilitation, 8(2), 104-112.

Jordan, R., \& Powell, S. (1994). Whose curriculum? Critical notes on integration and entitlement. European Journal of special need education, 9(1), 27-39.

Kearney, A., \& Kane, R. (2006). Inclusive education policy in New Zealand: Reality or ruse? International Journal of Inclusive Education, 10(2), 201-219.

Koegel, L. K., Koegel, R. L., Frea, W. D., \& Fredeen, R. M. (2001). Identifying early intervention targets for children with autism in inclusive school settings. Behaviour Modification, 25(5), 745-761. http://dx.doi.org/10.1177/0145445501255005

Loveland, K. (1991). Social Affordances and Interaction 11: Autism and the Affordances of the Human Environment. Ecological Psychology, 3(2), 99-119.

Loveland, K. (2001). Toward an ecological theory of autism. In J. A. Burack, T. Charman, N. Yirmiya, \& P. R. Zelazo (Eds.), The development of autism: Perspectives from theory and research. Hillsdale, NJ: Erlbaum.

McDonald, B. L. (2004). Inclusive education professional development: Working across cultures. In V. Heung, \& M. Ainscow (Eds.), Inclusive education: A Framework for Reform (pp. 83-96). Proceedings of the International Conference on Inclusive Education. Hong Kong: Centre for Special Needs and Studies in Inclusive Education, The Hong Kong Institute of Education.

Miles, M. B., \& Huberman, A. M. (1994). Qualitative data analysis: An expanded sourcebook (2nd ed.). Thousand Oaks, CA: Sage Publications.

NAS. (2003). How many people have autistic spectrum disorders? London: National Autistic Society.

Odom, S., Peck, C., Hanson, M., Beckman, P., Kaiser, A., \& Lieber, J. (2001). Inclusion at the preschool level: An ecological systems analysis. from http://www.newhorizons.org/spneeds/inclusion/information/schwartz1.htm

Ozonoff, S., Pennington, B., \& Rogers, S. (1991). Executive function deficits in high functionning autistic individuals: Relationship to theory of mind. journal of child psychology and psychiatry, 32(7), 1081-1105. http://dx.doi.org/10.1111/j.1469-7610.1991.tb00351.x

Parsons, S., Guldberg, K., MacLeod, A., Jones, G., Prunty, A., \& Balfe, T. (2011). International review of the evidence on best practice in educational provision for children on the autism spectrum. European Journal of Special Needs Education, 26(1), 47-63. http://dx.doi.org/10.1080/08856257.2011.543532

Pekrun, R., Goetz, T., \& Titz, W. (2002). Academic emotions in students' self-regulated learning and achievement: A program of qualitative and quantitative research. Educational Psychologist, 37(2), 91-105. http://dx.doi.org/10.1207/S15326985EP3702_4

Pianta, R. C. (2001). Implications of a developmental systems model for preventing and treating behavioural disturbances in children and adolescents. In J. A. Hughes, A. M. LaGreca, \& J. C. Conoley (Eds.), Handbook of psychological services for children and adolescents (pp. 23-42). Oxford: Oxford University Press.

Pianta, R. C. (2006). Classroom management and relationships between children and teachers: Implications for research and practice. In C. M. Evertson, \& C. S. Weinstein (Eds.), Handbook of classroom management: research, practice and contemporary issues (pp. 685-709). U.S.A.: Lawrence Erlbaum Associates.

Reiter, S. (2004). Life skills versus the skill for living: The circle of internationalization method for the enhancement of the "skill of living". In V. Heung, \& M. Ainscow (Eds.), Inclusive education: A Framework for Reform (pp. 241-254). Proceedings of the International Conference on Inclusive Education: Hong Kong: Centre for Special Needs and Studies in Inclusive Education, The Hong Kong Institute of Education.

Renn, K. A. (2003). Understanding the identities of mixed-race college students through a developmental ecology lens. Journal of College Student Development, 44(3), 383-403. http://dx.doi.org/10.1353/csd.2003.0032

Rogers, S. (2000). Interventions that facilitate socialization in children with autism. Journal of Autism and 
Developmental Disorders, 30(5), 399-409.

Sameroff, A. (1993). Developmental systems: Contexts and evolution. In P. H. Mussen (Ed.), Handbook of child psychology (pp. 237-294). New York: Wiley.

Sameroff, A. J., \& Feise, B. H. (2000). Models of development and developmental risk. In C. H. Zeanah (Ed.), Handbook of infant mental health (pp. 3-19). New York: The Guilford Press.

Strauss, A., \& Corbin, J. (1998). Basics of qualitative research: Techniques and procedures for developing grounded theory. Thousand Oaks: Sage publications.

Symes, W., \& Humphrey, N. (2012). Including pupils with autistic spectrum disorders in the classroom: The role of teaching assistants. European Journal of Special Needs Education, 27(4), 517-532.

Tudge, J., Gray, J., \& Hogan, D. (1997). Ecological perspectives in human development: A comparison of Gibson and Bronfenbrenner. Comparisons in human development (pp. 72-105). New York: Cambridge University Press.

Yin, R. K. (2003). Case study research: Design and methods. Thousand Oaks: Sage.

\section{Copyrights}

Copyright for this article is retained by the author(s), with first publication rights granted to the journal.

This is an open-access article distributed under the terms and conditions of the Creative Commons Attribution license (http://creativecommons.org/licenses/by/3.0/). 